\title{
Inovação e formação contínua de professores de ciências
}

\author{
Paulo Sérgio Garcia ${ }^{1}$
}

garciaps@usp.br

\section{Resumo}

Anualmente chegam muitas inovações às escolas, algumas delas interessantes, outras descontextualizadas e outras com o objetivo de formar professores. É comum, no Brasil, a utilização da inovação para solucionar problemas relativos à educação e, muitas vezes, utiliza-se o termo para legitimar projetos ultrapassados e padronizar práticas, desconsiderando a diversidade do contexto sociocultural. Pesquisas sugerem a superação desse modelo instrumental e sinalizam a necessidade de focar novas estratégias de desenvolvimento institucional. Este estudo analisou os efeitos de um projeto de inovação sobre a formação de professores de ciências. Foram entrevistados 11 docentes do ensino fundamental de três escolas públicas da cidade de São Caetano do Sul que participaram de um projeto de inovação no ensino de ciências. Os dados mostraram que a utilização da inovação como estratégia de formação de professores reduz a formação a poucos aprendizados. Alguns fatores redutores identificados relacionam-se à falta de apoio aos professores, de tempo para esses desenvolverem as mudanças, de recursos materiais e, sobretudo, de continuidade desses projetos.

Palavras-chave: Inovação; mudança; formação contínua de professores.

${ }^{1}$ Doutorando em Educação pela Faculdade de Educação da Universidade de São Paulo (USP). 


\section{Introdução}

No Brasil, anualmente, as escolas recebem inúmeras inovações e mudanças com vários objetivos, dentre eles, aqueles relacionados à formação de professores. Enquanto os estudos sobre os temas têm crescido no país, em outros contextos como no europeu e no norte americano, as contribuições já são bem significativas.

No contexto norte-americano, os trabalhos de Fullan (1992; 1993; 2001) foram impactantes para a compreensão da inovação e da mudança educacional. Na Europa, as pesquisas de Huberman (1973), Correia (1989), Benavente (1992), Hernandez et al. (2000), Thurler (2001), Carbonell (2002) e Cardoso (2003) trouxeram contribuições relevantes sobre o tema. No Brasil, Garcia (1980) organizou os primeiros trabalhos relativos à inovação educacional. Relacionado ao ensino de ciências, Krasilchik (1980; 2000) fez as primeiras aproximações e reflexões em relação à inovação e ao ensino de ciências. Moreira (1999) apresentou referências para melhor compreender a implementação de mudanças na escola, sugerindo a superação do caráter instrumental da inovação, visando essas mudanças.

O termo inovação em educação é, muitas vezes, usado para descrever melhorias na qualidade de ensino e, também, descrito como estratégia para a formação dos professores. No entanto, a inovação se afasta do pensamento simplista, não tem sentido unidimensional e se caracteriza mais como processo de um produto acabado.

Confundida, muitas vezes, com reforma, modernização ou mudança, a inovação tem sua definição mais relacionada a uma mudança deliberada e intencional com finalidades de melhorar o sistema educativo. Fullan (2001) caracteriza-a como um processo aberto e multidimensional.

A implementação de inovações é, geralmente, acompanhada de alguns obstáculos (FULLAN; HARGREAVES, 2000), marcada pela complexidade e pela impossibilidade de controlar seus efeitos (FULLAN, 2001; CARBONELL, 2002) ou impregnada por um caráter sedutor e enganador (CORREIA, 1989). Dessa forma, a rela- 
ção entre a inovação e a formação de professores não é simples e direta, principalmente, num país como o Brasil, em que a descontinuidade dos projetos caracteriza-se como uma das marcas das políticas educacionais.

Embora os objetivos da inovação se relacionem à melhora dos processos educacionais, incluindo a formação de professores, muitos estudos já sinalizaram a necessidade de ultrapassar esse caráter utilitário e focar o desenvolvimento institucional. Criando, dessa forma, condições para o desenvolvimento profissional (MOREIRA, 1999). Moreira afirma que não basta implantar inovações visando à formação de professores, é preciso ultrapassar essa perspectiva e superar o caráter utilitário das políticas de desenvolvimento profissional e institucional atreladas às inovações.

A ideia é que a inovação deixe de ser o foco principal para a valorização das escolas, dos professores e dos sistemas de ensino, que, nesse contexto, precisam ampliar suas competências para interagir de forma crítica com as inovações. Assim, eles poderiam aprender a viver e lidar com os contextos de mudança (MOREIRA, 1999; THURLER, 2001).

No entanto, frequentemente, observa-se no Brasil a inovação sendo assumida por muitos especialistas e políticos como tendo um fim em si mesma ou como uma estratégia, dentre outras, para solucionar problemas relativos à educação. Messina (2001), no contexto da America Latina, já relatava o uso indevido da inovação com o objetivo de legitimar projetos ultrapassados, padronizar políticas e práticas, desconsiderando a diversidade dos contextos sociais e culturais.

Assim, utiliza-se, muitas vezes, o termo inovação a fim de desenvolver diferentes tipos de projetos, dentre eles, aqueles com o objetivo de formação docente. Isso lança a seguinte reflexão: será que se essas inovações, que são impostas às escolas, contribuem para a formação docente? O objetivo deste estudo é precisamente o de verificar, na visão dos professores e por meio de análise documental, quais são os efeitos de um projeto de inovação sobre a 
formação contínua de professores de ciências. Participaram deste estudo, 11 professores de três escolas públicas que atuavam no ensino fundamental II da cidade de São Caetano do Sul, São Paulo.

\section{Um quadro da inovação pedagógica}

Com o avanço da ciência e da tecnologia, considerados importantes no desenvolvimento econômico, cultural e social, surgem, principalmente nos Estados Unidos, as primeiras demandas de inovação relacionadas à educação. Com isso, o ensino das ciências ganha maior relevância e é alvo de reformas e mudanças.

Na década de 1950, surgem nos Estados Unidos os primeiros projetos patrocinados pela National Science Foundation com o objetivo de transformar o ensino de ciências, focando na formação científica (HERNANDES, 2000). No decênio de 1960, foram realizados grandes investimentos em recursos humanos e criados projetos de física, biologia, química e matemática. A proposta buscava nas escolas secundárias jovens talentosos para as carreiras científicas com o objetivo de formar uma elite que pudesse garantir aos Estados Unidos a supremacia na conquista do espaço (KRASILCHIK, 2000).

Na década de 1950, no Brasil, uma das primeiras inovações que surgiu ficou a cargo do Instituto de Educação, Ciência e Cultura São Paulo (IBECC) e da Fundação Brasileira para o Ensino de Ciências (FUNBEC). As instituições tinham a incumbência de transformar o ensino de ciências, tornando-o mais prático e atualizando os conteúdos (KRASILCHIK, 1980).

Tem crescido o número de estudos sobre a inovação e a mudança educacional no Brasil. No entanto, eles são mais significativos e numerosos na Europa e nos Estados Unidos.

No contexto europeu, por exemplo, entre os vários trabalhos sobre o tema, destaca-se, na Espanha, as reflexões de Gonzáles y Escudero (1987) sobre as teorias e os processos de desenvolvimento da inovação. Os autores focaram também o conceito do termo inovação. A pesquisa de Hernandez et al (2000) que reuniu três 
estudos de caso sobre as inovações educativas ao longo do período de experiência da reforma de ensino espanhola. E o trabalho de Carbonell (2002) que situa a inovação das escolas e dos professores na confluência de uma aventura marcada por obstáculos e contradições por um lado e, por outro, possibilidades de aprendizagem e satisfações.

Na Suíça, os estudos de Huberman (1973) foram significativos para os primeiros entendimentos sobre o tema. O autor examinou com profundidade o conceito de inovação e o papel daqueles envolvidos em processos inovativos. No mesmo contexto, Thurler (2001) situou a escola como um nó estratégico de mudanças que pode tanto ser um catalisador da inovação quanto um obstáculo a ela. Em Portugal, os estudos de Correia (1989) sobre a inovação pedagógica e a formação de professores; de Cardoso (2003), sobre as relações entre as atitudes e a inovação; de Villar (1993) e de Benavente (1992) contribuíram para a ampliação das discussões sobre essa temática.

Nos Estados Unidos e também no Canadá, os trabalhos de Fullan $(1992 ; 1993 ; 2001)$ trouxeram inúmeras contribuições sobre a inovação e a mudança educacional. Esses estudos foram importantes e originaram novos conhecimentos sobre os significados das inovações, as fontes da mudança educacional e os processos de implementação e continuidade, além do papel dos atores - professores, alunos, diretores, pais etc. - envolvidos nas mudanças etc.

No contexto latino americano, vale salientar o trabalho de Blanco e Messina (2000), que fazem parte da equipe da rede de inovações educacionais da Organização das Nações Unidas para a Educação, Ciência e Cultura (Unesco) sobre o estado da arte das inovações educativas. O estudo teve como objetivo fornecer elementos de reflexão e análise sobre os processos de inovação educativa na América Latina durante a última década do século XX. As autoras, a partir da análise de 193 programas inovadores, investigaram como as inovações são concebidas, desenvolvidas e extintas e quais as principais tendências e diferenças entre os países e regiões. 
No Brasil, ganhou destaque, na década de 1980, o trabalho organizado por Garcia (1980), no qual são discutidos os problemas e as perspectivas da inovação educacional. Esse trabalho trouxe textos críticos sobre a definição da inovação educacional (GOLDBERG, 1980), análises críticas das mudanças pedagógicas acontecidas na organização curricular, nos métodos e técnicas de ensino, nos materiais escolares, na relação professor e aluno e na avaliação (FERRETTI, 1980). Além disso, o trabalho discute os limites e os alcances da inovação (WEREBE, 1980).

Vale citar ainda as pesquisas de Rios (1996). A autora fez uma reflexão sobre o significado da inovação no campo educacional, refletindo sobre compromisso com o novo ou com a novidade. O estudo de Mitrulis (2002) examinou as inovações acontecidas no ensino de nível médio, apontando elementos para sua melhor compreensão e para a criação de políticas de apoio e de orientação para as escolas. Também foram significativas as reflexões de Saviani (1980), que numa abordagem filosófica colocou que a compreensão da inovação relaciona-se às diferentes concepções de filosofia da educação. E também as reflexões de Wanderley (1980). Este, numa análise sociológica, afirmou que para um entendimento amplo da natureza da inovação educacional se faz necessário uma apreciação das relações da educação com o contexto social, tendo como ponto de partida as dimensões políticas, ideológicas e econômicas.

Especificamente relacionado ao ensino de ciências no Brasil, Krasilchik (1980) fez uma das primeiras análises sobre a inovação no ensino de ciências. Ele discutiu os movimentos que tinham como objetivo melhorar o ensino. Em outro trabalho, Krasilchik (2000), com o intuito de contribuir e ampliar o estudo de propostas de inovação, fez uma revisão histórica das propostas de reforma do ensino de ciências a partir da década de 1950. A autora analisa alguns projetos desde sua idealização nos órgãos normativos como parte de políticas públicas até o cotidiano das salas de aula. Moreira (1999) refletiu, de forma ampla, sobre a eficácia ou não da implementação de inovações no sistema de ensino e nas escolas. $\mathrm{O}$ 
autor apresentou referências para um melhor entendimento da implementação de mudanças nas escolas, sistematizando-as a partir de um estudo das reformas de ensino da Espanha e a implantação do currículo nacional na Inglaterra e País de Gales. Santos (2005) analisou as inovações no ensino de ciências e sugeriu inovações voltadas ao modelo de aprendizagem participativa por meio de investigações cientificas autenticas e do uso das novas tecnologias. Por fim, Garcia (2006) discutiu a inovação no ensino de ciências como um elemento de reflexão na formação de professores de ciências.

As primeiras tentativas de implementação das inovações tinham caráter prescritivo, pois se acreditava em uma lógica de generalização das experiências. Durante algumas décadas, os especialistas elaboraram os projetos de inovação com fases definidas para serem implementados nas escolas. Esse caráter prescritivo, que muitos dizem não ter mais espaço, ainda está presente em várias escolas brasileiras.

A década de 1970 traz um novo entendimento sobre as inovações, atribuindo destaque ao papel do professor. Passa-se a uma nova visão de que sem o envolvimento dos docentes as inovações ficariam na superficialidade ou, muitas vezes, essas mudanças acabariam por piorar os processos.

É comum encontrarmos, em geral, na literatura educacional brasileira e, em particular, naquela relacionada às ciências, a não diferenciação entre os termos inovação, reforma, modernização e mudança. No entanto, apesar da polissemia do termo, a inovação é caracterizada como uma mudança deliberada e intencional, objetivando melhorias no sistema educativo. Sua definição resulta da confluência de uma pluralidade de olhares e opiniões. É caracterizada como um processo aberto e multidimensional (FULLAN, 2001).

A modernização está relacionada ao ato de modernizar, ou seja, tornar moderno ou adaptar as necessidades modernas. Ela pode ou não trazer algum tipo de melhoria para o ensino. A modernização, que pode ser considerada no máximo uma mudança superfi- 
cial, liga-se à colocação, por exemplo, de novos microscópios no laboratório de ciências ou mesmo a reestruturação destes, mas isso não significa inovação. É possível dizer que existe uma relação entre a inovação e a modernização, no sentido que a primeira pode depender da segunda, mas o inverso não é verdadeiro.

Reforma e inovação também apresentam conceitos diferentes. González e Escudero (1987) e Carbonell (2002) dizem que a reforma liga-se à magnitude e à extensão, sendo uma mudança em grande escala concentrada no conjunto do sistema educativo. Enquanto que a inovação situa-se no nível mais real e limitado das escolas e das salas de aula. Hernandez (2000), no entanto, afirma que a diferença não deve ser colocada sobre a magnitude e extensão, mas sim sobre a incidência. As reformas relacionam-se às transformações, por exemplo, da legislação ou dos objetivos de ensino e não às mudanças das estratégias de ensino e aprendizagem.

As reformas têm objetivos políticos, econômicos, sociais e ideológicos e, muitas vezes, são apresentadas como panaceia dos problemas educacionais. Elas podem ou não gerar mudanças e melhorias no sistema educativo. Krasilchik (2000) diz que as maiores mudanças sociais, econômicas e culturais se refletem nas escolas e que a cada governo, se estabelecem novas ações reformistas.

Por fim, mudança e inovação também são termos diferentes. A mudança, que pode ser ou não impulsionada pela inovação, relaciona-se à passagem de uma situação ou posição para outra. Ela significa uma ruptura com a condição inicial e pode apresentar benefícios e ameaças àqueles envolvidos no processo. Se, por um lado, as mudanças se mostrarem ameaçadoras, as pessoas tenderão a resistir; no entanto, se ela for vista como benéfica e envolvida num movimento de colaboração, a resistência será menor. Assim, muitas vezes, as mudanças externas causam mais ameaças e, consequentemente, mais resistências do que aquelas que surgem internamente.

Messina (2001) acrescenta que a diferença entre mudança e inovação reside no campo de conhecimento. A primeira foi inicialmente uma preocupação da filosofia e depois das ciências sociais 
e naturais, e a segunda se revitalizou na área de administração durante as ultimas décadas do século XIX.

Barraza Macías $(2005 ; 2007)$, numa análise conceitual do termo inovação educativa a partir dos enfoques conceituais e dos componentes estruturais da definição, afirma que a maioria das definições são descritivas e que o termo está presente em todo o discurso educativo contemporâneo.

Fullan (2001), Carbonell (2002) e Cardoso (2003) têm definições muito parecidas para o conceito de inovação. Para esses autores, a inovação liga-se a um conjunto de intervenções, decisões com certo grau de intencionalidade e sistematização, que visam a transformar as atitudes, ideias, culturas, conteúdos, modelos e práticas pedagógicas. No entanto, como afirma Blanco e Messina (2000), ainda não há um marco teórico suficientemente desenvolvido sobre a inovação educativa.

São atributos da inovação: a intencionalidade, a originalidade, a novidade e a racionalidade. Outra característica da inovação é que ela não tem o mesmo sentido e nem os mesmos efeitos sobre aqueles que a promovem e aqueles que a colocam em ação. Seu caráter aberto tem múltiplos significados, despertando diferentes atitudes dos professores, que são manifestadas, em geral, em forma de aceitação ou resistência.

Fullan (2001) diz que as inovações possuem um conjunto de características interativas que afetam a fase de implementação. Estão entre elas, a necessidade da mudança, a clareza sobre as metas e os objetivos, a complexidade em relação à dificuldade enfrentada por aqueles que implementam os projetos e a qualidade e operacionalidade da inovação. O autor cita que as inovações precisam de atenção na qualidade desde o inicio do trabalho.

O processo de inovação e mudança apresenta três fases. A primeira é chamada de inicialização e consiste no processo que leva à adoção da inovação. A segunda fase é a implementação, dura mais ou menos dois ou três anos e envolve as primeiras experiências de tentar colocar as novas ideias ou reformas em prática. A terceira, que 
é uma extensão da segunda, é a continuação. Essa se relaciona à questão da incorporação e institucionalização das rotinas, bem como se a mudança foi construída ou será descartada (FULLAN, 2001). Fullan diz que essas fases estão interconectadas e que uma afeta a outra. A mudança, segundo ele, é um processo e não um evento.

O caráter aberto da inovação pode assumir múltiplos significados, despertando nos professores atitudes de aceitação ou resistência.

O conceito de atitude tem sido, segundo Cardoso (2002), um termo chave para aumentar a compreensão sobre a inovação. Há, segundo essa autora, uma relação particular entre as atitudes e a inovação, pois a inovação perfila-se aos hábitos, rotinas e comportamentos institucionalizados já estabelecidos. Essa é a razão das reações favoráveis ou desfavoráveis a ela. No processo de inovação, portanto, abandonam-se certas referências e isso ocasiona incertezas e perda temporária da competência. Assim, para que uma inovação aconteça, os professores têm de estar abertos e receptivos à mudança, desenvolvendo atitudes favoráveis a sua incorporação. A autora afirma, ainda, que sendo a inovação um processo inacabado, mais importante do que o produto, é a disposição permanente de inovar. Desse modo, a condição essencial de um projeto inovador reside na sua novidade e na sua capacidade de melhorar a prática vigente. Assim, aprender a recomeçar seria a primeira condição de todos os inovadores.

Segundo Fullan (2001), existem três possibilidades de inovação no campo educacional: aquelas relacionadas à utilização de novos materiais, currículos e tecnologias; o uso das novas abordagens de ensino, estratégias e atividades e a possibilidade de mudança nas crenças e pressupostos, que são subjacentes às práticas pedagógicas. O autor afirma ainda que as inovações mais bem sucedidas relacionam-se muito mais à utilização de novos materiais do que àquelas ligadas ao campo das novas abordagens de ensino ou à mudança das crenças dos professores. É muito mais fácil introduzir materiais do que mudar as crenças e as práticas dos professores. No entanto, para que as inovações ocasionem mudanças e melhorias 
prolongadas, é necessário interligar as três dimensões.

Todos os anos as escolas recebem algumas inovações não desejadas geralmente impostas politicamente e, às vezes, desconectadas do contexto escolar. É possível dizer que a maioria dessas inovações não estão relacionadas às três dimensões citadas acima e com isso acabam ficando na superficialidade. Fullan (2001) diz que o problema não é a falta de inovações, mas a presença de inúmeras delas, a maioria das vezes, desconectadas, episódicas, fragmentadas e superficiais em forma de projetos. Dessa forma, os professores são mais vítimas das inovações do que atores no processo de mudança.

As inovações podem ter diferentes sentidos. As verticais, que são produzidas por especialistas e prescritas às escolas, podem enfraquecer a autonomia dos professores e instituir a clássica divisão do trabalho entre aqueles que pensam e decidem e aqueles que fazem. Isso pode, também, diminuir a participação dos professores, propiciando a desvalorização do projeto inovativo e colocando-o em segundo plano, além de não alterar o ensino e a aprendizagem. Dentro dessa lógica vertical, poucos projetos tiveram continuidade. As inovações que têm o sentido contrário, ou seja, horizontal, e que, portanto, partem dos professores, tem mais chances de sucesso e de continuidade (CARBONELL, 2002).

A inovação, muitas vezes, é entendida e assumida por muitos especialistas e políticos como uma estratégia para os problemas educacionais, ou seja, como um fim em si mesma. Nesse sentido, ela tem, segundo Veiga (2003), um caráter regulatório ou técnico, sendo entendida como algo regulador, normativo, de controle burocrático e planejamento centralizado, onde as ideias e os ideais dos professores são deixados de lado. Dessa forma, o termo inovação é usado a fim de legitimar projetos descontextualizados da prática pedagógica docente. Resende e Fortes (2004) afirmam que as inovações pedagógicas são vistas como mecanismo salvador dos problemas educacionais e sociais, o que justificaria a entrada desses projetos desnecessários e distantes das reais necessidades de formação dos professores. 
Essa seria a face oculta da inovação, ou seja, seu caráter escamoteador onde se tenta legitimar ideias e projetos através do deslumbramento sem, no entanto, mostrar seus reais efeitos ligados, principalmente no Brasil, à falta de continuidade. Correia (1989) comenta sobre o caráter sedutor e enganador da palavra inovação. Sedutor quando a ele se integra o desejo de mudanças e de desenvolvimento da criatividade. Enganador porque oculta e não estimula a produção de referências sistematizadas a seus efeitos.

A falta de continuidade dos projetos de inovação, a impossibilidade de controlar os efeitos, a complexidade envolvida no processo, seu caráter sedutor, dentre outras coisas, têm feito com que autores sugerissem a superação desse modelo instrumental da inovação, onde ela é utilizada como o objetivo de, por exemplo, formar professores. O novo desafio seria o de focar em novas estratégias de desenvolvimento institucional, criando e fortalecendo as condições para o desenvolvimento profissional a fim de que os professores, as escolas e os sistemas aprendam a viver e lidar de forma crítica com as inovações e mudanças (MOREIRA, 1999; THURLER, 2001).

Fazer da escola um local em que os professores possam refletir e conduzir inovações e mudanças adequadas às necessidades de formação. Assim, os docentes passariam, juntamente com os especialistas, a dirigir seus processos de desenvolvimento profissional. Nesse sentido, Fullan e Hargreaves (2000) afirmam que os professores têm de exercer um papel central nos processos de mudança, pois as reformas fracassam quando esses são ignorados.

\section{O projeto de inovação em questão}

O projeto alvo da análise foi uma parceria entre a Secretaria de Educação da cidade e a Universidade de São Paulo.

A inovação, que teve início em 2002, trazia dois grandes objetivos: 1) a finalidade de desenvolver um inovativo ensino de ciências, combinando ciências e telecomunicações e integrando materiais, experimentos laboratoriais e demonstrações como a troca de 
informações entre escolas do Brasil; 2) a mudança da prática pedagógica do professor.

Os professores receberam treinamento e um material de apoio impresso que trazia diretrizes sobre o que eles tinham de realizar. Eles atuariam como orientadores dinâmicos, criando desafios para seus alunos num ambiente "equilibrador-desequilibrador". Seu maior desafio seria se tornar um inovador e para isso contava com a possibilidade de trocar informações e experiências com seus pares através da internet, podendo acessar o conhecimento de especialistas e tendo ainda acesso aos novos métodos de ensino. A ele caberia um papel crítico de aprender a organizar o material a sua disposição para a utilização na sala de aula. Para isso receberia treinamento, preparo e apoio institucional para ensinar com tecnologia avançada de forma bem sucedida.

O projeto de inovação deveria ser integrado aos conteúdos trabalhado pelos professores no dia-a-dia e levar os alunos a trabalhar como colaboradores dentro ou fora das escolas. Nesse trabalho os estudantes seriam levados a medir, coletar, avaliar, escrever, ler e relatar os dados de forma cooperativa com estudantes de diferentes escolas do Brasil e de outras partes do mundo.

\section{O contexto: a cidade, o projeto, as escolas e os professores}

A cidade de São Caetano do Sul, onde o projeto foi desenvolvido, tem sido alvo de outros estudos sobre a formação de professores (Garcia et al, 2006; 2009). O município tem aproximadamente 140 mil habitantes (2001) distribuídos sobre $15 \mathrm{~km}^{2}$. A cidade tem uma renda média que está entre as mais altas do país, bem com os índices econômicos e sociais. A menor taxa de mortalidade infantil do Brasil (11,3 por ano, em 2002), menos da metade da média do país (25,3 por ano, também em 2002). Os salários pagos aos professores das escolas estão entre os maiores do estado de São Paulo.

A cidade de São Caetano tem um dos melhores Índices de Desenvolvimento Humano (cerca de 0,919) do Brasil. Segundo a Or- 
ganização das Nações Unidas (ONU), o município tem o menor Índice de Exclusão Social do país $(0,864)$. De acordo com o Fundo das Nações Unidas para a Infância (Unicef), a cidade está entre os 60 municípios com o maior Índice de Desenvolvimento Infantil $(0,895)$.

Em relação às escolas, cabe salientar que todas elas contavam com: diretor, assistente de direção, coordenador pedagógico, coordenadores de área, orientador educacional, coordenador do projeto e de eventos e enfermeira. Todas elas tinham biblioteca, auditório, sala de artes, salas ambientes, laboratório de ciências, física, química, biologia e informática (que totalizavam mais de 50 computadores), além de três ou mais data-shows. Uma das escolas tinha, ainda, o selo das escolas solidárias do governo federal e participava das escolas associadas da Unesco. Cabe salientar que as escolas eram as mais procuradas pelos pais no município devido à qualidade da educação oferecida.

Quanto à formação dos professores, a configuração era a seguinte: três tinham licenciatura plena (dois em biologia e um em química) e oito possuíam licenciatura curta com complementação em: biologia (três), química (dois), matemática (três) (GARCIA et al, 2006). A maioria dos professores tinha algum tipo de pós-graduação. Eles atuavam em mais de 20 aulas semanais nas escolas e eram efetivos. No entanto, atuavam também em outras escolas.

Nesse contexto em relação à cidade, as escolas públicas, a formação e as condições de trabalho dos professores, acreditava-se encontrar boas condições para investigar os impactos do projeto de inovação na formação desses professores de ciências.

\section{Metodologia}

A questão central deste estudo era: quais foram os efeitos de um projeto de inovação sobre a formação contínua de professores de ciências que atuavam no ensino fundamental II. Para lidar com esta questão, foi utilizada a abordagem qualitativa de pesquisa. 
Segundo André e Ludke (1986), a pesquisa qualitativa interpreta as informações de uma forma ampla dentro do contexto no qual o problema de pesquisa se situa. Essa pesquisa envolve a obtenção de dados predominantemente descritivos, realçando mais o processo do que o produto e mostrando mais a perspectiva dos sujeitos da investigação do que a dos pesquisadores.

No ano de 2004 e 2007, utilizou-se a técnica de entrevista, com roteiro previamente estabelecido, a fim de coletar os dados junto a 11 professores de três escolhas públicas municipais. Esses docentes participaram do projeto de inovação no município entre os anos de 2002 e 2006.

Em 2007, quando o projeto de inovação já tinha terminado, foram entrevistados os mesmos professores a fim de saber se os aprendizados e as práticas estavam ainda sendo utilizadas no cotidiano das aulas com os alunos.

Os instrumentos de coleta de dados foram desenhados a fim de conhecer alguns efeitos da inovação sobre a formação dos professores. Quatro categorias foram previamente desenhadas e relacionaram-se a: 1) situando a inovação; 2) fatores impeditivos à inovação; 3) tipo de inovação e 4) origem da inovação.

A primeira categoria, "situando a inovação", analisou como o professor entende e situa a inovação em relação a sua formação contínua. A segunda, "fatores impeditivos à inovação", descreveu os obstáculos vividos pelos professores para a implementação e desenvolvimento da inovação. A terceira, "tipo da inovação", verificou quais as dimensões da inovação foram usadas, comparandoas com as já existentes na literatura e propostas por Fullan (2001). A quarta, "origem da inovação", investigou o surgimento do projeto e suas implicações na formação docente.

Paralelamente, foram analisados: os documentos da proposta de inovação, dentre outras coisas, os objetivos do projeto, as justificativas e os resultados esperados. Analisou-se também o contexto das escolas, em termos de estrutura administrativa e física, e a formação dos professores. 


\section{Análise e discussão dos dados}

Por meio da análise dos dados, foi possível compreender um pouco mais sobre a utilização de projetos de inovação com o objetivo de contribuir na formação de professores de ciências. Os resultados são apresentados abaixo de acordo com as categorias previamente estabelecidas.

\section{Situando a inovação}

Através da análise desta categoria, foi possível compreender que os professores situam a inovação sob uma multiplicidade de conceitos ligados, principalmente, à mudança, ao novo e ao aprendizado.

Apesar, no entanto, de os professores situarem o aprendizado como um dos aspectos importantes da participação no projeto, eles enfatizaram que outros fatores se sobrepuseram a esse, atenuando o impacto da inovação sobre as práticas pedagógicas. Dentre eles: a) a falta de espaço e tempo para discutir os problemas da implantação e do desenvolvimento da inovação na escola. De fato, muitos projetos de inovação são literalmente "jogados" para as escolas com pouco ou nenhum apoio aos professores. Isso, na maioria das vezes, ocasiona mais problemas do que alternativas de aprendizados;

b) a diferença entre as diretrizes da escola e as do projeto. A inovação se tornou algo isolado e além daquilo que os docentes já tinham que realizar no dia-a-dia. Os professores disseram que isso acabou aumentando a carga de trabalho;

c) falta de continuidade. Esse fator foi caracterizado por muitos como um dos principais problemas vividos durante o processo, pois a cada ano havia mudanças significativas sem que as primeiras tivessem sido assimiladas por eles;

d) discurso distorcido em relação à prática. Muitos professores comentaram que o que realmente era realizado no cotidiano das aulas, o trabalho efetivo com os alunos, era bem diferente das discussões realizadas com os mentores da inovação. Alguns chega- 
ram a dizer que já sabiam o que os coordenadores do projeto queriam ouvir. Por outro lado, disseram também que algumas de suas reivindicações mais básicas raramente eram atendidas. No entanto, como salienta Rios (1996), a inovação deve ser entendida como um compromisso conjunto de várias pessoas com o novo, um processo de construção coletiva onde todos os atores participam, debatendo o que necessariamente precisa ser mudado. Também Fullan e Hargreaves (2000) citam que as mudanças que não envolvem professores e lhes propicie formas de apoio, geralmente, acabam por piorar os processos.

Essas questões, segundo os docentes, contribuíram para atenuar os efeitos da inovação como estratégia na formação de professores e, consequentemente, poucos foram os impactos na mudança da prática pedagógica.

De fato, os dados advindos das entrevistas finais - de 2007, quando o projeto já havia terminado - mostraram que a maioria dos professores continuava a atuar de forma ainda "tradicional": sala de aula, giz, lousa, livro didático etc. Os aprendizados e práticas relacionadas ao projeto pararam de acontecer, segundo os professores, quando os mentores do projeto foram embora. Os quase seis anos de participação no projeto não foram suficientes para que as novas práticas pedagógicas fossem incorporadas no conjunto de estratégias dos docentes. Os professores justificaram os fatos dizendo que as pessoas perderam o interesse, o apoio diminuiu e, como disse um dos professores, "temos muitos outros projetos para realizar a pedido da direção".

Vale citar ainda que nem mesmo os recursos, uso dos computadores e da internet, que foram utilizados por vários anos, foram incorporados nas aulas dos professores. Em 2007, nenhum dos docentes utilizava-os em suas aulas diárias.

Outros estudos já sugeriram, para que os professores pudessem aprender e lidar com as inovações e mudanças, que a escola passasse a ser entendida como local de desenvolvimento profissional, um nó estratégico para a inovação (THURLER, 2001), uma organi- 
zação aprendente (FULLAN; HARGREAVES, 2000; THURLER, 2001) ou como comunidades profissionais de aprendizado (LEO, 2000; HORD, 1997a; BOYD, 1992; BOYD; HORD, 1994).

\section{Fatores impeditivos às inovações}

Os obstáculos à implantação da inovação foram agrupados em três grupos com os respectivos indicadores: pessoais, profissionais e contextuais. Pessoais: falta de interesse, medo e insegurança. Profissional: falta de estímulo, de apoio e tempo, excesso de trabalho, inabilidade daqueles que dirigem o projeto, falta de boa vontade da direção da escola, de treinamento (aprendizado) e de compreensão sobre a inovação. Contextuais: falta de recursos financeiros e materiais, incompetência política e incapacidade de manter a inovação (sustentabilidade).

Existe uma multiplicidade de fatores que obstaculizaram a implementação da inovação e, consequentemente, a efetiva formação dos professores.

Com relação aos fatores pessoais, podem-se compreender as respostas dos professores tendo em mente que a inovação se sobrepõe às rotinas e práticas já estabelecidas, ocasionando com isso diferentes reações, dentre elas medo e insegurança. De fato Cardoso (2002), ao afirmar que existe uma relação entre as atitudes e a inovação, cita que inovar é abandonar determinadas rotinas e, dessa forma, perder algumas referências. A autora afirma que a inovação traz incertezas e, por consequência, perde-se momentaneamente alguma competência e aumenta-se a sobrecarga de informações. Isso significa que a inovação vem acompanhada de riscos profissionais e também pessoais.

Os fatores profissionais apontados pelos professores foram a falta de apoio e de tempo, a inabilidade daqueles que dirigem o projeto, a falta de boa vontade da direção da escola e de compreensão sobre a inovação, além do excesso de trabalho. Esses são fatores que se aproximam muito dos obstáculos já catalogados e exis- 
tentes na literatura. Entre eles: a sobrecarga de trabalho (FULLAN; HARGREAVES, 2000), a essência individualista da profissão (FULLAN; HARGREAVES, 2000; THURLER, 2001); a organização e o funcionamento da escola (THURKER, 2001); o sentido sobre a inovação (HARGREAVES; EARL; RYAN, 2001; THURLER, 2001; FULLAN, 2001); o tamanho da mudança (HARGREAVES; EARL; RYAN, 2001), o tempo (HARGREAVES; EARL; RYAN, 2001; CARBONELL, 2002); a falta de apoio (FULLAN, 2001; CARBONELL, 2002), exclusão dos alunos e pais da mudança (HARGREAVES; EARL; RYAN, 2001), o funcionamento do diretor (THURLER, 2001), as inovações fracassadas (FULLAN; HARGREAVES, 2000; THURLER, 2001), a subutilização das competências dos professores (FULLAN; HARGREAVES, 2000).

Os fatores contextuais, encontrados neste estudo, também apresentam reflexos atenuantes sobre a formação docente à medida que a falta de recursos materiais e financeiros e a não continuidade desses projetos impedem a criação de uma cultura reflexiva que possa gerenciar as mudanças e a própria formação profissional.

\section{Tipo de inovação}

Esta categoria investigou as dimensões da inovação que estavam sendo utilizadas no projeto, relacionado-as com as já existentes na literatura e propostas por Fullan (2001). Esse autor diz que a inovação é multidimensional e que existem pelo menos três dimensões ou possibilidades de inovação: 1) aquelas relacionadas à utilização de novos materiais, currículos e tecnologias; 2) o uso das novas abordagens de ensino, estratégias e atividades e 3) a possibilidade de mudança nas crenças e pressupostos, que são subjacentes às práticas pedagógicas.

Através da análise documental, em que analisou-se as finalidades do projeto (introdução de novas tecnologias no ensino de ciências e à mudança na prática pedagógica dos professores), constatou-se que nos objetivos da inovação estavam embutidas as três 
dimensões citadas acima. No entanto, nos dados advindos das entrevistas, os professores reconheceram somente a primeira dimensão. Eles disseram que através da inovação proposta, realmente introduziram novos materiais e novas tecnologias, mas não reconhecem diferenças em suas formas de atuar com os alunos. Esse dado é relevante, pois segundo Fullan (2001), para que as inovações provoquem mudanças e melhorias duráveis, é preciso propor e relacionar as três dimensões.

As diferenças entre as dimensões propostas na inovação e aquilo que foi, efetivamente, reconhecido pelos professores pode ter diversas causas. Acredita-se que a inabilidade daqueles que dirigiram o projeto para trabalhar o sentido da inovação, os conflitos e a falta de continuidade sejam algumas dessas causas.

\section{A origem da inovação}

O projeto de inovação teve origem numa parceria entre a Universidade de São Paulo e a Secretaria Municipal de Educação, assim como muitos outros projetos que chegam às escolas, apresentando caráter externo e vertical. A inovação foi imposta às escolas sem uma prévia consulta para saber se ela era necessária ou não para a formação dos professores.

Veiga (2003) chama esse tipo de inovação de regulatória ou técnica. Marcada por um caráter regulador e normativo, não considera a diversidade de interesses dos professores e deixa-os de lado da concepção do projeto. Nesse processo, as preocupações ligamse à padronização, à uniformidade, ao controle burocrático e ao planejamento centralizado.

É possível classificar as inovações quanto à origem. Internas ou externas são para os projetos que se originam dentro da própria escola ou fora dela. Vertical e horizontal para as inovações que vêem de cima para baixo ou de baixo para cima.

As internas e verticais partem dos coordenadores pedagógicos, da direção da escola etc. As externas e verticais têm origem nas 
secretarias de educação, nas políticas públicas, na mídia, no avanço das tecnologias, nas universidades, nas empresas fabricantes de tecnologias, nas exigências do mercado de trabalho, na mudança de legislação, na pressão dos pais. As internas e horizontais partem dos professores, dos alunos etc.

Carbonell (2002) diz que as inovações horizontais e internas têm mais chances de sucesso e de continuidade, pois a participação dos professores é fundamental.

\section{Algumas implicações finais}

Os resultados deste estudo sinalizam a necessidade de se ter muita cautela ao assumir e utilizar esse tipo de inovação como estratégia para a formação de professores de ciências do ensino fundamental. No projeto de inovação pesquisado, os resultados foram pequenos em virtude do tempo e dos recursos investidos.

As análises advindas das três primeiras categorias "situando a inovação", "fatores impeditivos" e o "tipo da inovação" mostraram que esse modelo instrumental de inovação, aqui analisado, para a formação de professores de ciências, não é suficiente para levar os docentes a mudanças duradouras em suas práticas pedagógicas. De fato, esses professores não passaram a desenvolver um inovativo ensino de ciências utilizando as novas tecnologias e também não mudaram seus modos de agir e atuar com os alunos, esses eram os dois objetivos principais da inovação.

No entanto, há que se destacar que outras variáveis como as características das escolas (cultura) e sua organização são, sem dúvida, outros fatores condicionantes da inovação.

Assim, entende-se que essa compreensão da inovação como estratégia para a formação de professores se articula muito mais no campo do discurso do que na prática, devendo, portanto, ser substituída por outra que fortaleça a escola e seus docentes.

Os dados advindos da literatura especializada sobre o assunto já haviam sinalizado a necessidade da mudança do foco da 
implementação de inovações para a ampliação da capacidade institucional de inovar. Moreira (1999) cita que o foco no desenvolvimento institucional tem por objetivo fazer com que as escolas e os órgãos oficiais locais ampliem suas competências no sentido de diagnosticar e lidar com os problemas e com as inovações, bem como criar condições para o desenvolvimento profissional.

Segundo o mesmo autor, focar no desenvolvimento institucional por causa do fator descontinuidade das políticas públicas significa, dentre outras coisas, fortalecer as escolas e os professores, questionar tanto as reformas que visam padronizar as práticas educativas como as formas de gestão das reformas e das inovações.

Os resultados deste estudo mostraram, ainda, que a falta de continuidade, a falta de apoio e de tempo, o funcionamento do diretor e das equipes pedagógicas, a falta de recursos materiais e financeiros, as diferenças entre os objetivos da escola e os da inovação são alguns aspectos que reduziram os efeitos da inovação sobre a formação dos professores. Isso porque a inovação, dentre outras coisas, necessita de recursos adequados, apoio e, efetivamente, ela tem de ser baseada na cultura da colaboração.

De fato a falta de continuidade caracteriza-se como um dos grandes problemas da educação brasileira em geral e das políticas relacionadas ao ensino de ciências em particular. Na opinião dos professores, esse foi um dos fatores atenuantes dos supostos benefícios que o projeto de inovação traria sobre suas formações. Isso vai ao encontro das afirmações de Fullan (1992; 1993) que diz que projetos de inovação bem sucedidos precisam de ações bem organizadas entre as escolas, os sistemas de ensino locais e as universidades, requerendo para isso pelo menos uma década. Ou seja, é necessário tempo e continuidade para que as mudanças aconteçam nas organizações das escolas e na formação dos professores.

As implicações deste estudo devem ser consideradas de forma mais ampla. As autoridades competentes, que elaboram políticas para o ensino de ciências, e os especialistas que implementam inovações precisam considerar essa realidade. As inovações anuncia- 
das e acontecidas não têm melhorado a formação dos professores de ciências, que ainda tem no livro texto seu principal apoio (BIZZO et al, 2007), e nem o desempenho dos alunos, o que pode ser visto nos resultados de exames internacionais como é o caso Programa Internacional de Avaliação de Alunos (PISA). Em 2006, o Brasil ficou na $52^{\circ}$ posição no PISA. Se isso não vem acontecendo é preciso que se questione, dentre outras coisas, esse modelo em que a inovação se constitui no motor para a formação de professores.

Nesse sentido, os professores precisam olhar criticamente para essas inovações e mudanças, analisando se elas implicam, efetivamente, em melhorias de suas formações. Eles devem, dentre outras coisas, questionar a concepção, os fundamentos teóricometodológicos, os objetivos, os autores e os implementadores da inovação a fim de fazer um balanço crítico sobre esse contexto. É preciso compreender como e onde as mudanças irão se processar e quem será afetado por elas. Por fim, é necessário ampliar o debate e descobrir a quem, efetivamente, esse tipo de modelo interessa.

É preciso, claramente, o desenvolvimento de novas pesquisas para compreender mais a respeito dos efeitos dessas inovações sobre a formação dos professores de ciências. Estudos que envolvam, inclusive, um numero maior de professores, outra forma de organização da inovação, várias escolas etc. No entanto, tendo em vista os resultados deste estudo, é pelo menos possível refletir mais atentamente sobre os discursos daqueles que advogam, propositadamente ou não, sobre a criação de políticas de formação de professores, tendo a inovação como estratégia. 


\section{Referências}

ANDRÉ, M. E. D. A.; LUDKE, M. Pesquisa em educação:

abordagens qualitativas. São Paulo: EPU, 1986.

BARRAZA MACÍAS. A. Una conceptualización comprehensiva de la innovación educativa. Innovación Educativa, v. 5, n. 28, p. 1931, 2005.

Análisis conceptual del término innovación educativa.

Revista Visión Educativa IUNAES, v. 1, n. 3, 2007.

BENAVENTE, A. As ciências da educação e a inovação das práticas educativas. In: SPCE (Ed.). Decisões nas politicas e práticas educativas. Porto: SPCE, 1992.

BLANCO, G. R.; MESSINA, G. Estado del arte sobre las innovaciones educativas en América Latina. Colombia: Convenio Andrés BelloUNESCO. 2000.

BIZZO, N. et al. Brazilian science textbooks and canonical science. In: IOSTE - INTERNATIONAL MEETING ON CRITICAL ANALYSIS OF SCHOOL SCIENCE TEXTBOOK, Tunisia, 2007. Proceddings... Tunisia:[ s.n.] 2007, v.1. p. 301-309.

BOYD, V. Creating a context for change. Issues about Change, v. 2, n. 2, 1992.

BOYD, V.; HORD, S. Schools as learning communities. Issues about Change, v. 4, n. 1, 1994.

CARBONELL, J. A aventura de inovar: a mudança na escola. Porto Alegre: ArtMed, 2002. 
CARDOSO, A. P. As atitudes dos professores e a sua relação com a inovação pedagógica. In: . Receptividade à mudança e à inovação pedagógica: o professor e o contexto escolar. Porto: Edições ASA. (Coleção Perspectivas actuais/Educação). p. 22-33, 2002.

. Educação e inovação. Revista Millenium on-line. Viseu Portugal. Ano 6. Março de 2007. Disponível em:<http:/ / www.ipv.pt/millenium/pce6_apc.htm>. Acesso em:04 fev. 2003.

CORREIA, J. A. Inovação pedagógica e formação de professores. Porto: Edições Asa. 1989.

FERRETTI, C. J. A inovação na perspectiva pedagógica. In: GARCIA, W. E. (org.). Inovação educacional no Brasil. Problemas e perspectivas. 3. ed. Campinas: Editora dos Autores Associados, 1980, p. 61-90.

FULLAM, M. The new meaning of educational change. New York: Teaches' College Press, $3^{\text {nd. }}$ ed. 2001.

. Change forces: probing the deaths of educational reform. London: The Falmer Press. 1993.

. Successful school improvement. Buckingham: Open University Press, 1992.

FULLAN, M.; HARGREAVES, A. What's worth fighting for: working together for your school. Toronto: Ontario Public School Teachers' Federation, 1991.

A escola como organização aprendente: buscando uma qualidade para a educação. Porto Alegre: Artes Médicas, 2000.

GARCIA, P. S. Inovação no ensino de ciências. In: ENCONTRO 
PERSPECTIVAS DO ENSINO DE BIOLOGIA, 10,, ENCONTRO REGIONAL DE ENSINO DE BIOLOGIA (MT/MS/SP), 1., São

Paulo. Caderno de Programas e Resumos, v. 1, p. 161, 2006.

GARCIA, P. S.; et al. Two case studies about science teachers' initial preparation. In: IOSTE SYMPOSIUM, 12. , Malaysia. Proceedings..., p. 31-36, 2006.

GARCIA, P. S.; MALACARNE, V.; BIZZO, N. O percurso formativo, a atuação e condições de trabalho de professores de ciências de duas regiões brasileiras. Acta Scientiae (ULBRA), v. 11, p. 119-140, 2009.

GARCIA, W. E. (org). Inovação educacional no Brasil. Problemas e perspectivas. 3. ed. Campinas: Autores Associados, 1980.

GOLDBERG, M. A. A. Inovação educacional: a saga de sua definição. In: GARCIA W. E. (Coord). Inovação educacional no Brasil. Problemas e perspectivas. São Paulo: Cortez, 1980, p. 183-194.

GONZÁLEZ,M. T.; ESCUDERAOMUÑOZJ. M. Innovación educativa. Teorías e procesos de Desarollo. Bacelona: Humanitas, 1987.

HERNANDEZ, F. (org). Aprendendo com as inovações nas escolas. Porto Alegre: Artes Médicas, 2000.

HARGREAVES, A.; EARL, L.; RYAN, J. Educação para a mudança. Recriando a escola para os adolescentes. Porto Alegre: Artes Médicas, 2001.

HORD, S. M. Professional learning communities: What are they and why are they important? Issues about change, v. 6, n. 1, 1997a. Disponível em: <http:/ / www.sedl.org/change/issues/ issues61.html>. Acesso em: 04 de ago.de 2004. 
HUBERMAN, A. M. Como se realizam as mudanças em educação: subsídios para o estudo da inovação. São Paulo: Cultrix, 1973.

KRASILCHIK, M. Inovação no ensino de ciências. In: GARCIA W. Inovação educacional no Brasil. Cortez. 1980.

. Reformas e realidade: o caso do ensino das ciências. In: Perspec, São Paulo, v.14, n. 1, p.85-93, 2000.

. Caminhos do ensino de ciências no Brasil. Em Aberto, Brasília, ano 11, n. 55, 1992.

LEO, T.; D'ETTE C. Lauching professional learning communities: Beginning actions. Issues About Change, v. 8, n. 1, 2000.

Disponível em: <http://www.sedl.org/pubs/catalog/items/ cha39.html. Acesso em: 04 de ago. de 2004.

MESSINA, G. Mudança e inovação educacional: notas para reflexão. Cadernos de Pesquisa, São Paulo, n. 114, p. 225-233, 2001.

MITRULIS, E. Ensaios de inovação no ensino médio. Cadernos de Pesquisa, São Paulo, v. 116, p.217-244, jul. 2002.

MOREIRA A. F. Is it enough to implement innovations in educational systems. In: Educação e Pesquisa, São Paulo, v. 25, n.1, p. 131-145, 1999.

RESENDE, L. M. G.; FORTES, R. M. C. Mudancas e inovações na formação continuada dos docentes. Disponivel em: <http:/ / www.anped.org.br/reunioes/28/textos/gt08/gt081096int.rtf>. Acesso em: 16 dez. 2004. 
RIOS, T. A. Significado de inovação em educação: compromisso com o novo ou com a novidade? Campinas: PUCCAMP, 1996. (Séries Acadêmicas, v. 5).

SANTOS, A. M. P. Inovações no ensino de ciências e na educação em saúde: um estudo a partir do Projeto Finlay. 2005. Dissertação (Mestrado em Ensino de Ciências). Faculdade de Educação Universidade de São Paulo, 2005.

SAVIANI, D. A filosofia da educação e o problema da inovação em educação. In: GARCIA, W. E. (Coord.). Inovação educacional no Brasil. Problemas e perspectivas. São Paulo: Cortez, 1980, p. 15-29.

THURLER, M. G. Inovar no interior da escola. Porto Alegre: Artmed, 2001.

VEIGA, I. P. A. Political-pedagogic innovations and project: an emancipating or regulatory relationship? In: Cad. CEDES, Campinas, v. 23, n. 61, p. 267-281, 2003.

VILAR, A. M. Inovação e mudança na reforma educativa. Porto: Edições Asa. 1993.

WANDERLEY, L. E. W. Parâmetros sociológicos da inovação. In: SAVIANI, D. A filosofia da educação e o problema da inovação em educação. In: GARCIA, Walter E. (Coord.). Inovação educacional no Brasil. Problemas e perspectivas. São Paulo: Cortez, 1980, p. 30-54.

WEREBE, M. J. G. Alcance e limitações da inovação educacional. In: GARCIA, W. E. (org) Inovação educacional no Brasil. Problemase perspectivas, 3. ed. Campinas: Autores Associados, 1980, p. 265-288. 


\title{
Innovation and science teachers' continuing education
}

\begin{abstract}
Every year arrives at schools many innovations some interesting, others decontextualized and others with the aim at providing teachers' continuing education. It is common, in Brazil, the use of innovation to solve problems related to education, and often the term is used to legitimize oldfashioned projects and standardize practices, ignoring the diversity of sociocultural context. Studies suggest overcoming this instrumental model and indicating the need to focus on new strategies for institutional development. This study examined the effects of an innovation project on the science teachers' continuing education. We interviewed 11 teachers from elementary school to three schools in the city of São Caetano do Sul, who participated in a project of innovation in science teaching. The data showed that the use of innovation as a strategy for teachers' continuing education reduces the learning process. The lack of support, time, resources and materials, mainly the lack of continuity, are some of these factors that reduce science teachers' continuing Education.
\end{abstract}

Keywords: Innovation; change; science teachers'; continuing education. 